DOI 10.26886/2523-6938.1(1)2017.7

UDC 575.17:78

\title{
EPIGENETIC BASES OF MUSIC MODULATION
}

\section{A. Bocharov, PhD, MD, DSc}

Medical Centre «ORTO-DENT/BIO-DERM», Ukraine, Odessa

The subject matter of research are the special features of the emotional reactions of patients to application of music modulation. Purpose of the work is to compare results of the action of the different types of musical modulation on the psychophysiological state of patients. Among the bioenergetic mechanisms important are the epigenetically determined factors of ligand-receptor interactions at the level of neurons on the centers of brain, which correspond to emotional reaction.

Keywords: bioenergetic and ligand- receptor mechanisms reaction to the acoustic (musical) actions.

${ }^{1}$ B. A. Бочаров, доктор медицинских наук, профрессор; Эпигенетические основы музыкомодуляции / ${ }^{1}$ Медицинский центр «ORTO-DENT/BIO-DERM», Украина, Одесca;

Предмет исследования - особенности эмоциональных реакций больных на применение музыкомодуляции. Цель работы - сравнение результатов воздействия разных видов музыкальной модуляции на психофизиологическое состояние больных. Среди биоэнергетических механизмов влияния музыки на человека важное значение могут иметь эпигенетически детерминированные фракторы, а так же лиганд-рецепторные взаимодействия на уровне нейронов центров головного мозга, отвечающих за эмоциональное реагирование. 
Ключевые слова: биоэнергетические и лиганд-рецепторные механизмы реагирование на акустические (музыкальные) воздействия, эпигенетика.

В медицине музыку нередко используют в качестве средства коррекции психоэмоционального состояния человека, при этом многочисленные методики музыкотерапии предусматривают как целостное, так и изолированное использование музыки в качестве ведущего фрактора воздействия, или как дополнительного, сопровождающего другие коррекционные приемы для усиления их воздействия и повышения эффрективности. На сегодняшний день в мире созданы специализированные центры музыкальной терапии, и даже - международные объединения по этой проблеме (Doctor Music, Music and Medicina), в которых сотрудничают специалисты из многих стран; выпущен первый «Международный словарь музыкотерапии» (Канада, Capilano University, 2013). Научно-исследовательские разработки прошли тщательную экспертизу и утверждены в соответствующих департаментах медицины для практического применения. Сформулированы теории и концепции музыкотерапии (например, «нейро-гуморально-резонансная теория»), разработаны специальные методики - антивозрастной музыкотерапии («МезоФорте-Технологии»), музыкорефлексотерапии и обезболивания («АкуТон-Терапия»), алгоритмы, регулирующие уровень гормонов в крови, и даже активность клеток крови, вплоть до стволовых клеток гемопоэза.

В то же время, практическое применение музыки в ряде случаев оказывает не только позитивное, но и негативное влияние, что диктует необходимость диффреренцированного подхода к ее использованию в системе комплексного лечения больных. В частности, наши 
собственные наблюдения показали, что у больных с поражениями кожи, В патогенезе которых имеют место расстройства психофизиологического состояния, применение музыки оказывало неоднозначный эффрект: воздействие т. н. «живой» музыки у больных людей оказывало позитивный эмоциональный эффрект у $90 \%$, в то время как использование Т. Н. «компьютеризированной» музыки (применение аудиодисков и др.) у 25\% больных вызывало негативные эмоции, и такое лечение им отменялось.

В литературе имеются многочисленные концепции влияния музыки на человека, однако они нуждаются в дальнейшем анализе, в том числе - с учетом новых достижений в медико-биологических науках и, в частности, в эпигенетике.

Концептуальными положениями научной музыкотерапии являются такие:

1) музыка рассматривается одновременно и как искусство, и как фризическое явление, но механизмы и эфрфективность музыкотерапии оцениваются методами доказательной медицины;

2) для понимания механизмов действия музыкотерапии исследуются особенности комплексных реакций организма на акустические воздействия (нейропсихологические, гормональные, ресрлекторно-фризиологические, адаптационные, регенеративные);

3) изучаются фризиотерапевтические аспекты акустического воздействия на организм слышимого спектра (16 - 20000 Гц) и инфразвуков в комплексе С алгоритмами и интенсивностью воздействий;

4) продолжается внедрение открытых новых закономерностей воздействия музыкотерапии в медицинские технологии (лечебнооздоровительные, реабилитационные, профилактические). 
Вокалотерапия - это специальная система тренинга и лечения, базирующаяся на принципах бельканто и доказано, что она эфффективно действует на кровообращение и функцию внутренних органов, активность головного мозга и настроение, одновременно способствует развитию личности и творческих способностей.

Имеются работы, свидетельствующие о том, что мажорные тональности и быстрый темп повышают показатели электропроводимости точек акупунктуры, а минорные мелодии и медленный темп - их понижают. Различные музыкальные инструменты и тембры оказывают избирательное действие на внутренние органы и системы (например, «струнные» - коррегирующе влияют на точки акупунктуры т. н. «меридиана сердца» и в мягкой форме снижают артериальное давление у гипертоников). Б. Келлер отмечал, что колеблющаяся струна скрипки не создала бы никакого звука, если бы не было деревянного корпуса, который колеблется вместе со струной, представляя собой резонатор. Но на нас постоянно воздействуют внешние колеблющиеся частоты - геомагнитное поле самой Земли и другие модуляции. Организм человека - как «тело скрипки», и ответ возникнет лишь тогда, когда колебания приводят к резонансу. Не только питание, дыхание, но и эмоции постоянно возбуждают колебания молекул благодаря воздействию силовых полей. Как неправильное дыхание и питание, так и определенные стойкие негативные эмоции приводят к искажению этих колебаний, вплоть до деструктивных процессов.

В науке продолжаются исследования даже в отношении воздействия музыки на опухолевые клетки, микробные клетки и другие клетки организма. На практике широко используется музыкотерапия в качестве психокоррекции для беременных, матерей кормящих грудью, для детей с психическими и моторными расстройствами. 
В музыкотерапии в значительной степени используют достижения В различных видах науки, особенно касающихся проблем биоэнергетики. Музыка не существует в изоляции от других видов знаний, и даже в квантовой теории М. Планка музыкальная природа рассматривается в качестве «строительного материала»; образ действия атомного ядра, с точки зрения пропорций музыкальных интервалов, описал В. Крюгер - специалист в области атомной физики и теории музыки.

Использование синергетического подхода и принципа интеграции различных знаний показало, что существуют аналогии между процессом перевода на язык музыки биоритмов (в том числе рождения человека) и механизмами бессознательного реагирования т. е., источник, дающий начало акустическим и физиологическим явлениям в процессе восприятия (а возможно - и «рождения») музыки находится в сфрере бессознательного, где происходят закономерности энергетических процессов, преобразующих психическое напряжение в звуковую материю. Это совпадает и с концепцией Э. Курта (музыкального психолога) о психоэнергетической природе движения звуков.

Результатом таких исследований стало утверждение нового понятия «индивидуальная музыка» или - «музыкально-энергетический ключ», который представляет собой музыкальный фрагмент, состоящий из цепочек интервалов, расположенных в определенной последовательности. По данным психолога А. Манегетти, рассматривающего биоритмы рождения человека как проект природы, переведенный на язык музыки, вышеуказанный «музыкальный фррагмент», стремящийся к идентичности, представляется «звучащей мандалой» - символа самодостаточности и внутренней целостности, что связано с качеством поступающего энергоинформационного 
сигнала, когда организм осуществляет нормальное управление своими функциями.

В контексте эпигенетики индивидуальная музыка рассматривается как логика чередования консонансов и диссонансов в музыкальном фрагменте, что означает существование в энергетическом проекте природы человека гармоничного принципа, который отличает фальшивое и гармоничное. Это гармоничное начало присутствует с рождения, но его «включение» зависит от многих факторов, которые и объясняет эпигенетика - наука, исследующая изменения активности генов, не затрагивающих структуру ДНК, многие из которых владеют информацией о структуре клетки и способах ее функционирования и активны в течение всей жизни человека. Эпигенетика объясняет как окружающая среда может влиять на «включение» и «выключение» генов (это так называемые «эпигенетические переключатели», которые свойства человека могут менять как в лучшую, так и в худшую сторону).

Предполагается наличие некоего «информационного канала», по которому открывается доступ к гармоничному началу, а язык музыки осуществляет это на бессознательном уровне. Роль вышеуказанного эпигенетического переключателя и выполняет так же вышеуказанная «индивидуальная музыка» (музыкальный энергетический ключ). Терапевтическое воздействие этого «ключа» не зависит от музыкальных предпочтений и музыкального образования пациента. Важен индивидуальный подбор тембров инструментов для фрагментов индивидуальной музыки.

Таким образом, даже на уровне генов музыка имеет значение:

1) исследования т. н. «явления возврата» Ферми-Паста Улана доказали существование волнового типа памяти генома; 
2) ДНК человека способна взаимодействовать с командами, имеющими специфическую лингвистическую природу и специфическую мелодическую (вибрационную) окраску;

3) структура биополя ДНК имеет электромагнитную и акустическую природу, являясь своеобразной антенной, записывающей приход информации и имеющей «волновой иммунитет»!!!

Со стороны чувствительных к звукам функциональных систем отмечаются рефрлекторные психофизиологические реакции и резонансные отклики на «полевые» (в т. ч. - биополей) воздействия. При этом, с точки зрения синергетики, правильно организованные резонансные воздействия (акустические) согласовываются с внутренними свойствами нелинейной системы, результатом чего становятся сильные ответные реакции. Вышеуказанный музыкальный энергетический ключ (индивидуальная музыка), с современной научной точки зрения, было бы точнее обозначить сокращением, В котором ключевым словом будет «ligand» (от англ. lighter - зажигалка)

«БЭЛА» (Био-ЭНЕРГЕТИЧЕСКИЙ ЛИганд АкустическИй) который резонирует с природной (существующей на уровне биополей) гармоничной программой энергетических и фризических состояний человека, и слушатель бессознательно располагает тем запасом смысла, который есть в звуковой информации, для установления определенного контекста, а слушание (!!!) становится процессом декодирования этой информации, восстанавливая память клеток.

Следует учитывать и феномен т. н. эйдетизма продолжающихся психофизиологических реакций возбуждения в нервном аппарате после прослушивания музыки, от чего зависит продолжительность последействия музыкотерапии. Именно «индивидуальная музыка» дает наиболее продолжительный эффеект: 
положительных

ЭМОЦИОНАЛЬНО-ЧУВСТВЕННЫХ

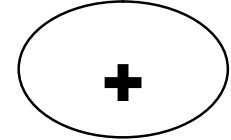

гармоничных

Реакций

СОМАТИЧЕСКИХ

Симптомов

Музыку, с медицинской точки зрения, относят к направлениям с использованием рецептивных технологий (лиганд-рецепторные отношения являются одним из важных фризиологических френоменов в организме). Но это так же важное хронобиологическое направление в медицине, которое занимается коррекцией функционального состояния человека и его гомеокинетических систем. Это расширяет возможности лечения с нормализацией саморегуляции на всех уровнях организма конкретного человека, воздействуя фризическими фракторами на основе биологически обратной связи, с учетом интегральной целостности организма. Биоритмологическое использование музыки особенно эфффективно для улучшения засыпания и снятия эмоционального напряжения.

Таким образом, в общих чертах мы с Вами уточнили значение методики оздоровления музыкой (песней) с разных точек зрения, но эта проблема нуждается в дальнейших исследованиях со стороны многих специалистов не только в области медицины и психологии, но и других отраслей науки. Но, даже это предварительное сообщение подтверждает тезис о том, что отношение к изучению влияния музыки на человека без понимания современных достижений науки в отношении медико-биологических проблем обречено на неуспех, и наоборот - тесная интеграция знаний в отношении нейрофизиологии, эпигенетики, лиганд-рецепторных отношений, рефлекторных реакций человека со знаниями в отношении природы музыки и ее воздействия на организм человека может стать одним из перспективных направлений современной науки о биоэнергетике. 

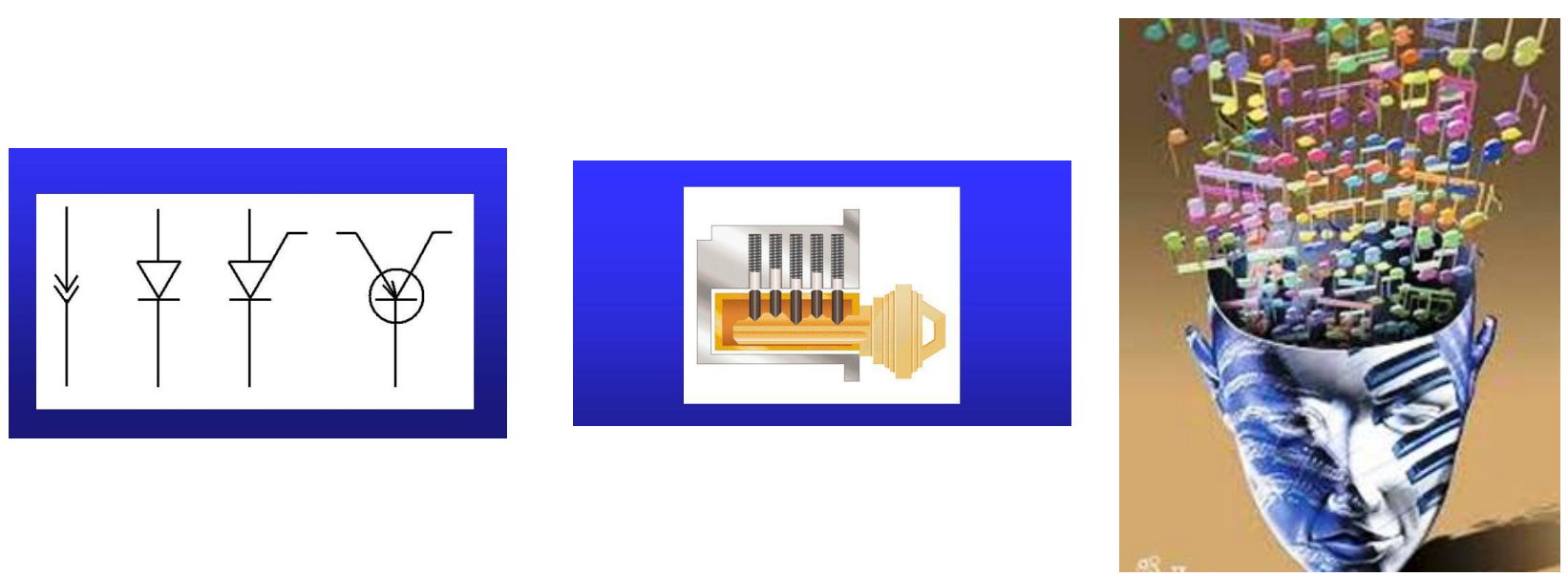

(http://mrmarker.ru/p/page.php?id=812)

(http://wavegenetics.info/

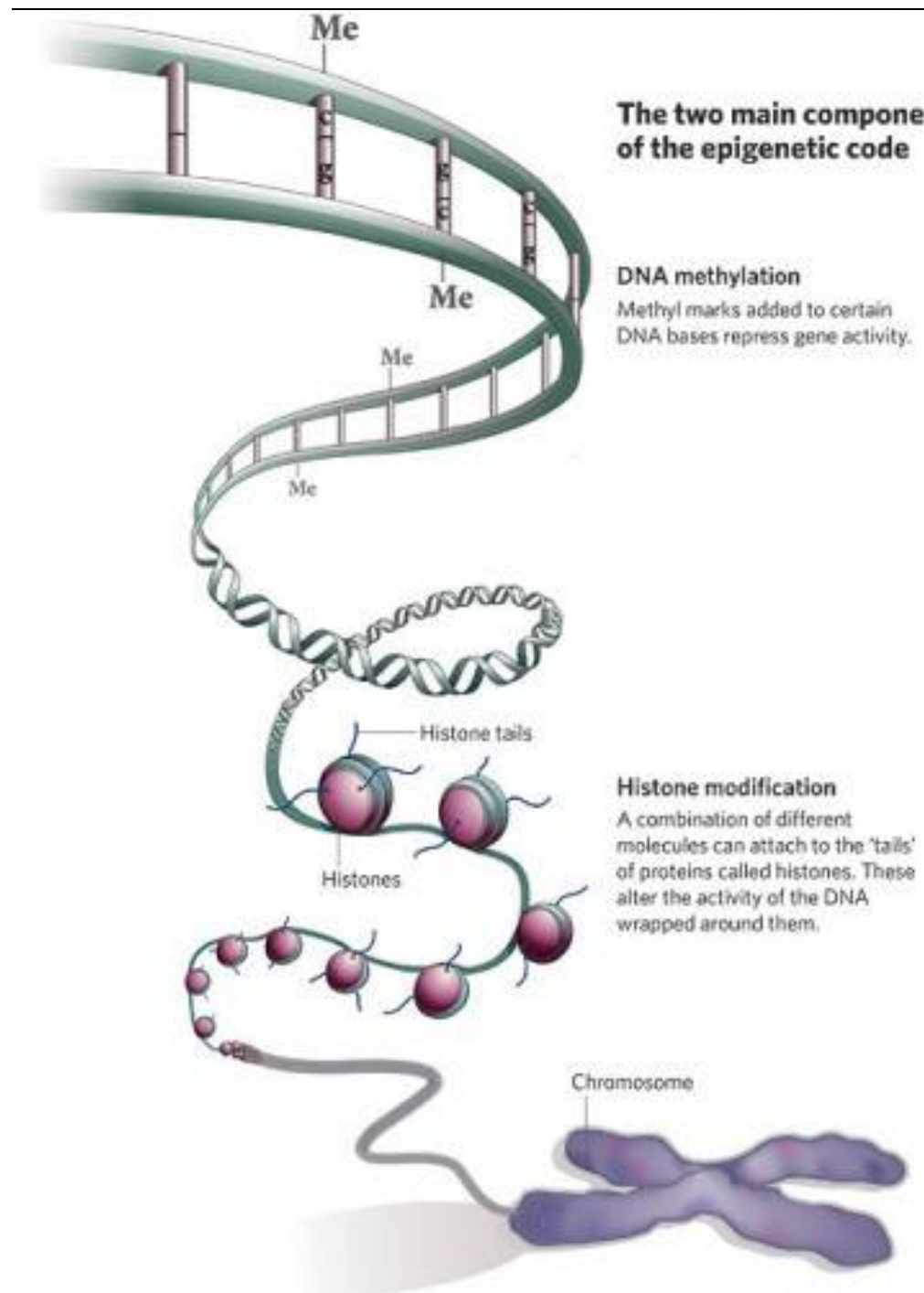

(http://kolesha.ru/vnutrikletochnaya-evolyuciya-dnk/)

Рис. Биоэнергетический лиганд акустический (BELA) и эпигенетические механизмы музыкомодуляции 


\section{תumepamypa:}

1. Брин В. Б. Физиология человека в схемах и таблицах: Учебное пособие / В. Б. Брин. - СПб.: Лань, 2016. - 608 с.

2. Мирошник E. В. Динамика адаптационных возможностей организма у больных с расстройствами адаптации и эндогенными депрессиями в процессе использования резонансной цветозвуковой технологии «Цветозвуковая матрица «Антистресс» / E. B. Мирошник, В. А. Орлова, М. В.Чиж // Теоретические и клинические аспекты применения биорезонансной и мультирезонансной терапии: Тезисы и доклады ХХІІ Международной конфреренции. - М.: ИМЕДИС, 2016. - C. 235-239.

3. Клюев А. С. Музыка. Философия. Синергетика / А. С. Клюев. СПб.: Астерион, 2012. - 200 C.

4. Сальникова T. В. Биоэнергокорректор или «А Ваша песенка спета?» / Т. В. Сальнокова, И. Б. Новицкая // Теоретические и клинические аспекты применения биорезонансной и мультирезонансной терапии: Тезисы и доклады XXII Международной конфреренции. - М.: ИМЕДИС, 2016. - С. 57-59.

5. Шушарджан C. В. «Музыкальнополевая мезотерапия» инновационная технология омоложения кожи и оздоровления. Биофизические фракторы лечебно-оздоровительных эфрфектов / C. В. Шушарджан, P. С. Шушарджан // Теоретические и клинические аспекты применения биорезонансной и мультирезонансной терапии : Тезисы и доклады ХХІІ Международной конфреренции. - М.: ИМЕДИС, 2016. - C. 66-74.

6. Шушарджан С. В. Руководство по музыкальной терапии. - М.: Медицина, 2005. - 450 c.

7. Epigenetics / D. Allis, T. Jenuwein, D. Reinberg, M.-L. Caparros. - Cold Spring Harbor Laboratory Press, 2007. - 502 p. 
8. Regulation of Gene Expression by Small RNAs / R. K. Gaur, J. J. Rossi (Eds). - CRC Press, 2009. - 440 p.

\section{References:}

1. Brin V. B. Fiziologiya cheloveka $v$ skhemah $i$ tablicah: Uchebnoe posobie [Human Physiology in Schemes and Tables: A Tutorial]. Saint Petersburg: Lan', 2016, 608 p. [in Russian].

2. Miroshnik E. V., Orlova V. A., Chizh M. V. Dinamika adaptacionnyh vozmozhnostej organizma $u$ bolnyh $s$ rasstrojstvami adaptacii i ehndogennymi depressiyami $v$ processe ispol'zovaniya rezonansnoj cvetozvukovoj tekhnologii «Cvetozvukovaya matrica «Antistress». Teoreticheskie $i$ klinicheskie aspekty primeneniya biorezonansnoj $i$ mul'tirezonansnoj terapii: Tezisy $i$ doklady XXII Mezhdunarodnoj konferencii. Moscow: IMEDIS, 2016, pp. 235-239. [in Russian].

3. Klyuev A. S. Muzyka. Filosofiya. Sinergetika [Music. Philosophy. Synergetics]. Saint Petersburg: Asterion, 2012, 200 p. [in Russian].

4. Sal'nikova T. V., Novickaya I. B. Bioehnergokorrektor ili «A Vasha pesenka speta?». Teoreticheskie $i$ klinicheskie aspekty primeneniya biorezonansnoj $i$ multirezonansnoj terapii: Tezisy $i$ doklady XXII Mezhdunarodnoj konferencii. Moscow: IMEDIS, 2016, pp. 57-59. [in Russian].

5. Shushardzhan S. V., Shushardzhan R. S. «Muzykal 'nopolevaya mezoterapiya» - innovacionnaya tekhnologiya omolozheniya kozhi i ozdorovleniya. Biofizicheskie faktory lechebno-ozdorovitel 'nyh ehffektov. Teoreticheskie $i$ klinicheskie aspekty primeneniya biorezonansnoj $i$ multirezonansnoj terapii: Tezisy $i$ doklady XXII Mezhdunarodnoj konferencii. Moscow: IMEDIS, 2016, pp. 66-74. [in Russian].

6. Shushardzhan S. V. Rukovodstvo po muzykal'noj terapii [Management on the Musical Therapy]. Moscow: Medicina, 2005, 450 p. [in Russian]. 
7. Allis D., Jenuwein T., Reinberg D., Caparros M.-L. Epigenetics. Cold Spring Harbor Laboratory Press, 2007, 502 p. [in English].

8. Gaur R. K., Rossi J. J. (Eds). Regulation of Gene Expression by Small RNAs. CRC Press, 2009, 440 p. [in English]. 